\title{
Cultural Continuity in EFL Teaching in International Higher Education: From a Discourse Perspective of Chinese Learners
}

\author{
YANG Wenhui ${ }^{1} \&$ CHEN Linhan ${ }^{1}$ \\ ${ }^{1}$ International College, Guangdong University of Foreign Studies, Baiyun Dadao Bei 2\#, Baiyun District, \\ Guangzhou, Guangdong, China
}

Correspondence: YANG Wenhui, International College, Guangdong University of Foreign Studies, Baiyun Dadao Bei 2\#, Baiyun District, Guangzhou, Guangdong, China. Tel: 86-20-3620-9685. E-mail: 198910321@oamail.gdufs.edu.cn

Received: August 26, 2014 Accepted: November 21, 2014 Online Published: January 20, 2015

doi:10.5539/elt.v8n2p196 URL: http://dx.doi.org/10.5539/elt.v8n2p196

\begin{abstract}
This paper presents an ethnographic study of the application of cultural continuity in English as Foreign Language (EFL) teaching in International College, GDUFS China. Based on Holliday's (2001) findings and Brown's (2000) twelve "manifestos" together with interviews of the Chinese learners, the authors investigate the discoursal elements used by both native EFL teachers (NEFLTs) and Local Chinese EFL teachers (LEFLTs) in international programs from a discourse perspective of Chinese university learners. They find that the practice of cultural continuity in classrooms by LEFLTs and NEFLTs demonstrates different preferences and patterns which form an essential feature of cooperative teaching for international higher education. NEFLTs' adaptation to local learning environment and LEFLTs' application of foreign teaching modes may present an integrated mode which displays both cultural continuity and discontinuity of English and local learning culture at the same time.
\end{abstract}

Keywords: cultural continuity, discoursal elements, NEFLTs, LEFLTs, international higher education

\section{Introduction}

Teachers and learners in EFL contexts in different cultures might preconceive their beliefs or notions about language teaching and learning, which are shaped by their own cultural backgrounds. In decades, there are many studies about learners in EFL contexts, regarding their learning cultures, motivation, procedures and outcomes by both Western scholars (e.g., Hofstede, 1986; Marton, et al., 1997) and Chinese scholars (e.g., Qi \& Ding, 2011; Yang \& Sun, 2012; Yang, 1999) mainly from linguistic perspectives. As for EFL classroom teaching, it has been greatly influenced by changing views on the nature of teaching and learning which are reflected in the objectives and content of teaching, as well as the teaching materials, and teachers' and learners' roles in the classroom. Although there have been changes in practices of higher education over the past twenty years, it is still traditionally believed (e.g., Brown, 2000; Holliday, 1997, 2001) that cultural continuity in relation to curriculum design and course development should be required. The cultural continuity is usually summarized within the teaching framework of curriculum design from a form-focused, or structural approach, to a meaning-focused, or communicative approach. They have embedded cultural continuity in the way teaching pedagogy is described, from structural syllabuses to notional-functional syllabuses and more recently, to content/topic-based syllabuses, and continuity in the ways in which higher education is conducted in different universities of different countries. The continuity has profound implications for the internationalization of higher education, although their far-reaching effects are only gradually becoming apparent. However, the cultural continuity concerning teaching and learning modes has not been well addressed in academic research cross-culturally. Furthermore, the difficulties in developing cultural continuity in the teaching and learning environment of higher education in China, especially for the teachers who are involved in international programs of cooperative education, are expected, since they have generally worked in a Chinese cultural environment but are required to educate the students who will go abroad to complete their degrees. Few scholars conduct research from a discourse perspective to illustrate the cross-cultural differences of teaching by native and non-native teachers of international programs of higher education.

In this research, the authors will, from a discourse perspective of Chinese learners, compare the teaching modes of NEFLTs (native EFL teachers) and LEFLTs (local EFL teachers) who have been working for international 
cooperative programs in China, with an endeavor to analyze the research questions:

1) What discoursal elements are applied by NEFLTs and LEFLTs respectively to maintain the (Western) cultural continuity in international cooperative programs in China?

2) What factors shape the use of (Western) cultural continuity issues in the teaching process by NEFLTs and LEFLTs in the international cooperative programs?

No one doubts that teaching modes are greatly associated with cultures, although there is little agreement on what people mean by the idea of culture in the first place. The need to provide cultural continuity for the teachers and students has, in the past, been based upon content and syllabus design in internationalization of higher education. Therefore, examining issues of cultural continuity in current international higher education is essential, and having an understanding of the cultural continuity and its development is vital in the teaching and learning environment of changing cultures and language education, especially for the research of today's EFL study.

\section{Cultural Continuity and Its Studies}

The notion of "continuity" develops from Aristotle's idea that a living thing "has within it a principle of change and staying unchanged" (Wiggins, 1980; O'Sullivan-Lago et al., 2008). According to Chandler and Proulx (2006), although the levels of analysis for studying individual and cultural continuity are different, the notion of "continuity" supports a conceptual movement between the individual and cultural. They argue that cultural continuity is psychologically important. Cultural, at the group level, "consists of shared elements which provide the standards for perceiving, believing, evaluating, communicating and acting among those who share a language, a history, and a geographic location" (Ferdman \& Horenczyk, 2000, p. 84). As for "cultural continuity", its definition is taken from Jacob (1996), who is interested in the way in which the teacher mediates between a "foreign" lesson and the "local" orientation of her or his students. It can be used to refer to a broader aim which has become common in EFL in the last decade - to be sensitive to the cultural expectations of the "recipients" of innovation, whether they are students or teachers encountering new teaching methodologies, or stakeholders in curriculum projects (Holliday, 2001). Ethnographically, Spradley (1980) comprises cultural continuity as (Holliday, 1997, pp. 212-213):

- An extended study of a specified cultural environment. This could be almost anything - a community, a place of work, a small group of people, a set of documents, or even a single person or activity.

- An interpretive and qualitative approach where significant features of the culture are allowed to emerge. This involves direct observation of behavior which is written up into an ethnographic record.

- The emergent significant features of the culture lead the researcher to focus on a particular direction and to develop categories which provide the structure for description and analysis.

- There is no claim to objectivity. There is simply a collection of illuminating instances which can contribute to the wider picture. The scientific rigor and system are in the discipline of the research procedure which comprises tight rules concerning how the researcher relates to and writes about the research environment.

These arguments constitute a holistic description and analysis of all the features which the researchers have found significant regarding the application of cultural continuity in teaching and learning. As Thornton (1988) sees it, a holistic description about cultural issues becomes a testimony as much to the researchers' own perspectives as to the features the researchers have noted. Moreover, from an ethnographical and cross-cultural perspective, Holliday (1997, p. 236) compares the language teaching in China and India, analyzing the behavior and physical environment of the culture of each classroom. His study demonstrates that aspects of a popular view of the "communicative" connected with group-work, oral practice and teacher withdrawal may be questioned. Instead, cultural continuity between traditional and innovative forms emerges as an essential feature of successful communicative language teaching. He suggests that cultural continuity between communicative language teaching and more traditional forms is necessary if innovation is to succeed. This may be achieved in a variety of ways, but the maintenance of a lecturer's authority and status may be the key in university settings. However, there are other two schools of thought about the extent to which cultural continuity can be adopted in, say, developing an international program. One could be those international programs in which all curriculums, teaching and learning methods follow the Western patterns. The other side could be those international programs in which parts of the curriculums, teaching and learning methods use the Western patterns, while parts of them are maintained to be the local patterns. Regarding the cultural continuity in teaching, Shamim (1996) argues that the changes advocated in current teaching in different cultural backgrounds are essentially 'Western" in nature, and unsuited to other contexts, such as in Pakistan. Phillipson (1992) also points out that the Western culture, the developed world, or the centre, as he calls it, is always trying, as it has always tried, to impose its educational 
ways of pedagogical thinking on the developing world, or, in his terms, the periphery. As Brown (2000) sees it, the teaching and learning behavior which the typical Western specialist might not consider to be communicative may well be so in different cultural backgrounds, such as in Eastern countries. These phenomena represent local interpretations of the meaning of "cultural continuity", and are more likely to survive precisely because they emerge from the local learning and teaching culture. Holliday (2001) proposes that the basic idea of cultural continuity is that a particular innovation is adjusted to integrate the best possible fit with the host environment. It is a two-way process in which the innovation needs to be supported by data from the host environment (Figure $1)$.

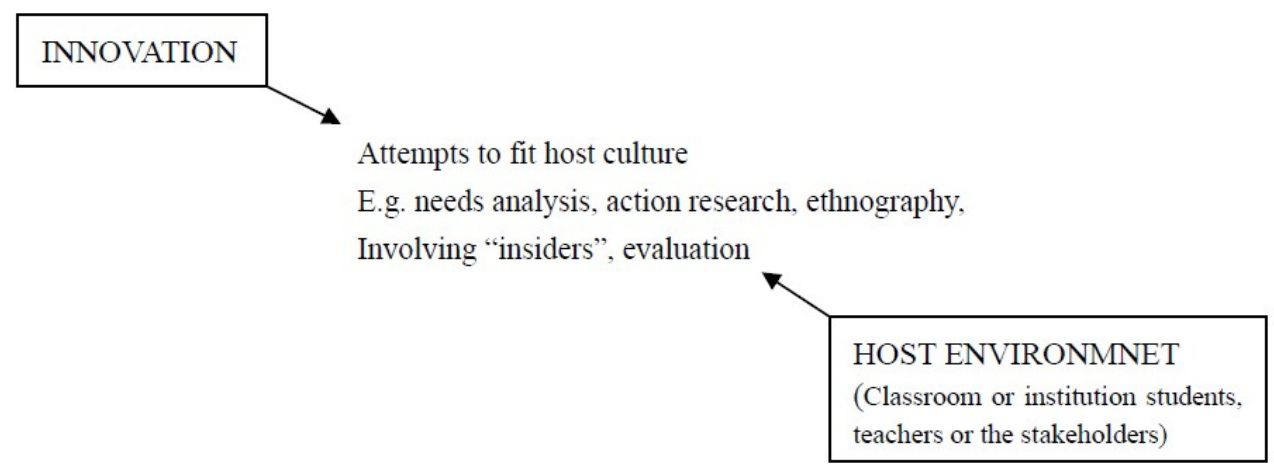

Figure 1. Cultural continuity (Holliday, 2001, p. 170)

There are clear indications within the lessons that considerable cultural continuity has been created between the more traditional and innovative scenarios. Behavioral and environmental links exist between the traditional and the new which facilitate the cultural absorption of the latter (Jacob, 1996). However, Brown (2000) does notice the conflicts related to cultural continuity in ELT while teachers implement changes in their classrooms. Based on a public statement of the key points of their methodology, he summarizes 12 "manifestos":

Table 1. Manifestos of teaching methodology (Brown, 2000, p. 231)

\section{Problem-solving/Discovery learning}

Pair-work rather than group work

Seat work

Time-on-task

Teacher questioning and eliciting language

Encouraging learner questions

Teacher's skill as explainer and in presenting information

Use of English for classroom management

Teaching large classes

Handling errors

Using local materials effectively and imaginatively

Evaluating materials and practice: telling good materials from bad, good practice from bad practice.

According to Brown (2000, p. 231), “... these action points would draw from the tradition that existed and from the new inputs in a way in which they could find harmony. Seat work, time-on-task, and teacher as explainer are strong traditional points, ...pair-work and group work are given precedence. Particular attention is to be paid to handling large classes, to teachers' questions, and to the effective and imaginative use of local materials." He admits that the above strategies are not supposed to be some sort of magic wand to solve the problems of maintaining cultural continuity in teaching and the teachers are not in universal agreement with the strategies laid out above, however, a number of ways of resolving conflict which, while not free of problems, does at least 
justify a degree of optimism. His research provides guidelines for the teachers who are involved in the programs of internationalization of higher education but the real empirical results of the application of cultural continuity in teaching by teachers of different backgrounds have not been identified and analyzed, which may provide an insight for international teaching cooperation and internationalization of higher education research.

\section{Research Method}

The present study draws on a database of interviews, questionnaires and observations, as well as from field notes and records of the classroom lectures and group meetings. The perspective on teaching modes is socio-cultural: both LEFLTs and NEFLTs are situated in the actual practice of international cooperation of higher education in a specific cultural environment in China. This research has been closely integrated into the Holliday's (2001) cultural continuality mode, as a form of progressive and empirical action research. The objectives are related to three aspects of the cultural continuity phenomena: enactment, experiences and impact, which were associated with the teaching modes applied by LEFLTs and NEFLTs.

\subsection{Subjects}

The data was collected in the International College of Guangdong University of Foreign Studies (GDUFS), the largest training centre for studying abroad and collaborating with the partner universities abroad in China. Students who have completed their language training and foundation courses in the International College and reached the entry requirement (passing the prerequisite modules and meeting a range of the IELTS 6.0 requirements) can further their education in the cooperative universities overseas of their choice, receiving a bachelor's degree awarded by the partner universities. The data constructed and used in this study included:

Table 2. Background information about the subjects

\begin{tabular}{|c|c|c|}
\hline & Number & Background information \\
\hline \multirow[t]{2}{*}{ Students } & \multirow[t]{2}{*}{100} & Year 1 students in international college (three groups) \\
\hline & & IELTS 5.0 above or equivalent \\
\hline \multirow{2}{*}{$\begin{array}{l}\text { Local Chinese } \\
\text { EFL teachers }\end{array}$} & \multirow[t]{2}{*}{4} & Have been teaching English for 6 to 10 years in GDUFS \\
\hline & & Graduated from UK universities with MA degrees \\
\hline \multirow{2}{*}{$\begin{array}{l}\text { Native English } \\
\text { EFL teachers }\end{array}$} & \multirow[t]{2}{*}{4} & Have been teaching university students for 5 to 10 years in China \\
\hline & & Graduated from UK universities with BA or MA degrees \\
\hline
\end{tabular}

- Three groups of Chinese students in International College who were taught by four local EFL teachers and native EFL teachers from 2010-2013,

- Eight observations have been conducted in four local EFL teachers' and four native EFL teachers' classrooms,

- A hundred interviews have been conducted from 2010-2013 (the authors met the students each week during the semesters),

- A hundred students completed the questionnaire.

\subsection{Research Instrument}

Three instruments were employed. The first one was interviews, referring to a Discourse Completion Test (DCT) which included brief descriptions of situations followed by blank spaces for appropriate responses. The reason why the DCT was chosen as this research instrument was that "DCT is a controlled elicitation method which meets the demands for cross-cultural comparability" (Blum-Kulka et al., 1989), and "it allows researchers to control the variables of the situation, thereby providing a consistent body of data". DCT has been proved to be quick and efficient in gathering a large amount of data (Kasper 2000). Details concerning how these instruments were developed are elaborated in the following sections. The second instrument was the questionnaire, ranging from 1 (different)-5 (same) to evaluate the degree of cultural continuity applied by both LEFLTs and NEFLTs. The third one was authors' observation by sitting in classrooms to support the analysis of the statistics.

\section{Results and Discussion}

Within the international programs, cultural continuity is identified in four areas. First, cultural continuity can reside in the classroom activities and tasks within each activity, and from one activity to another and from one task to another. Second, cultural continuity potentially resides within communicative acts during the learning and 
teaching either at the "macro" level in terms of the whole lesson and its "micro" sequences of interaction, or within the structure of discourse in terms of the "macro" communicative act with its own coherent sequence of utterances. Third, cultural continuity is provided through the ideational system. At the "macro" level, the learner may have access to cultural continuity of the syllabus, while at the "micro" level, the learner can have access to conceptually or notionally cultural continuity. Cultural continuity may be realized through a refinement of syllabus design - the refinement of a teaching and learning concept, for example, can imply a refinement of the teaching modes in international programs, and vice-versa. Finally, cultural continuity can reside within a skill repertoire or a cycle of skill-use during an international program of higher education. All may be inherent in a program of international higher-education. In the following study, the authors are to identify the most significant discoursal elements associated with cultural (dis)continuity in the teachings, followed by the analysis of cultural factors which exert impact on the cultural continuity application in EFL teaching in China.

\subsection{Statistical Analysis of the Identified Discoursal Elements}

Based on the DCT interviews and observations, the top ten discoursal elements were identified concerning cultural (dis)continuity in the EFL teaching (see Table 3).

Table 3. Discoursal elements of cultural continuity identified in EFL classroom

\begin{tabular}{ll}
\hline Discoursal Element & Cultural Issues \\
\hline 1. Teacher centered/student centered & $\begin{array}{l}\text { Teaching time division per session: Student-centered or } \\
\text { teacher-centered, students' activities in classroom. } \\
\text { 2. Examples used in the classroom }\end{array}$ \\
$\begin{array}{l}\text { The numbers of examples used in teaching: Chinese local examples or } \\
\text { English examples. }\end{array}$ \\
$\begin{array}{l}\text { Frequency of mistake correction in classroom: correcting every mistake } \\
\text { or picking up some mistakes which might influence understanding. } \\
\text { Textbook used: local English textbooks, references or authentic English } \\
\text { textbooks, references. }\end{array}$ \\
4. Use of textbooks & $\begin{array}{l}\text { Language used for teaching: English or Chinese. } \\
\text { Critical level: accepting or evaluating, encourage or discourage. }\end{array}$ \\
5. Language used in classroom & Homework arrangement: one hour or more than one hour per day. \\
6. Critical thinking & Term papers requirement: words limit ranging from 300-2000 words. \\
7. Time spent on homework & Classroom management: tight control or loose control, such as control \\
8. Academic writing & on chatting, going out to toilet, and mobile phone use. \\
9. Classroom control & Teaching mode: creative teaching or traditional teaching. \\
10. Teaching innovation &
\end{tabular}

In the past, students' views on cultural continuity and its related teaching patterns were less considered in EFL research. Researchers paid more attention to government views, teachers' views and linguists' views. Their views regularly dominated what were applied as the conceptions of internationalization of higher education. However, students currently are quick to recognize that cultural continuity in teaching of international programs, based on their learning experience in a variety of lectures taught by both LEFLTs and NEFLTs, including their comments on teachers' working styles in contexts which are both cultural and cognitive.

The discoursal elements listed in Table 3 have been designed as questionnaires for students to answer. Their replies demonstrated clear differences regarding the teaching modes of LEFLTs and NEFLTs, ranging from 1-5 scale. From the ten elements, we have selected four elements for detailed statistical study: element 2, 3, 8 and 10, demonstrating that their applications formed the base of cultural (dis)continuity applied by both LEFLTs and NEFLTs in China EFL teaching environment. The scales concerned in the present study were processed for reliability analysis and the results were summarized in Table 4. 
Table 4. Reliability statistics of the questionnaire (Number: 100)

\begin{tabular}{lll}
\hline Scale & No. of the elements & Mean Cronbach $\alpha$ \\
\hline Teacher centered/student centered & 1 & 0.60 \\
Examples used in the classroom & 2 & $\mathbf{0 . 7 8}$ \\
Mistake correction & 3 & $\mathbf{0 . 6 6}$ \\
Use of textbooks & 4 & 0.63 \\
Language used in classroom & 5 & 0.61 \\
Critical thinking & 6 & 0.53 \\
Time spent on homework & 7 & 0.55 \\
Academic writing & 8 & $\mathbf{0 . 7 4}$ \\
Classroom control & 9 & 0.63 \\
Teaching innovation & 10 & $\mathbf{0 . 7 6}$ \\
\hline
\end{tabular}

The reliability for each scale applied in the present study seemed satisfying, and the mean cronbach's alpha of each factor was $0.78,0.66,0.74$ and 0.76 respectively. Although the mean cronbach's alpha of element 3 (mistake correction) and element 8 (academic writing) were a little lower, they were all above 0.65 . Therefore, the questionnaire designed showed an internal consistency and was reliable to investigate the cultural continuity applied by both LEFLTs and NEFLTs in the present research, concerning the four elements: 2, 3, 8, 10. To examine the research questions, the descriptive statistical results were displayed in Table 5 which was to describe the main features of a collection of data in quantitative terms and aimed at quantitatively summarizing a data set: the mean, standard deviation, variance, and standard error were calculated.

Table 5. Descriptive statistics of the four cultural elements in EFL teaching

\begin{tabular}{lllll}
\hline Teachers & Elements & Mean & Std,d & Variance \\
\hline NEFLT & 2 & 2.435 & 0.840 & 0.705 \\
& 3 & 2.780 & 0.607 & 0.372 \\
& 8 & 2.169 & 0.695 & 0.601 \\
& 10 & 2.281 & 0.956 & 0.919 \\
LEFLY & 2 & 2.062 & 0.877 & 0.771 \\
& 3 & 2.686 & 0.534 & 0.287 \\
& 8 & 2.021 & 0.893 & 0.401 \\
& 10 & 2.154 & 0.846 & 0.718
\end{tabular}

Note: NEFLT $=$ native $\overline{\text { EFL teacher, LEFLT }=\text { local EFL teacher, } 2=\text { examples used }}$ in the classroom, $3=$ mistake correction, $8=$ academic writing, $10=$ teaching innovation.

Table 5 showed that the mean score of element 3 was 2.780 , followed by element 2 (2.435), element 10 (2.281), and element 8 (2.169). Standard deviations of the four elements were $0.607,0.840,0.956$ and 0.695 respectively. However, as for LEFLTs, the highest mean score was element 3 (2.686), followed by element $10(2.154)$, element 2 (2.062), and element 8 (2.062). The standard deviations of each parameter were $0.534,0.846,0.877$ and 0.893 respectively. From the results, it seemed that both NEFLTs and LEFLTs preferred to consider element 3 as their priority in their teaching. Mistake correction was often viewed as a traditional means for LEFLTs, which was, however, discouraged in Western teaching environment because many NEFLTs worried about that corrections might be viewed as interruptions to damage students' self-confidence according to a NEFLT in GDUFS. NEFLTs correction behavior in international programs in GDUFS showed that they adapted to traditional Chinese teaching methods and hoped their correction could improve their accuracy in language learning.

Further analysis was conducted with kruskal-wallis test with the help of software SPSS17.0 to rank all data from 
all participants together. In the present study, the kruskal-wallis test was used to compare each parameter's means rank as well as to examine whether there were significant differences among the four parameters. If the result of kruskal-wallis test showed $p>0.05$, the authors would draw the conclusion that there was no significant difference among the four parameters, and vice versa.

Table 6. Cultural continuity elements applied by NEFLTs and LEFLTs

\begin{tabular}{llll}
\hline & Elements & N & Mean Rank \\
\cline { 2 - 4 } Scores of four elements & 2 & 33 & 115.47 \\
applied by NEFLT & 3 & 33 & 98.55 \\
& 8 & 33 & 155.32 \\
& 10 & 33 & 104.48 \\
Scores of four elements & 2 & 33 & 103.65 \\
applied by LEFLT & 3 & 33 & 176.38 \\
& 8 & 33 & 96.08 \\
& 10 & 33 & 95.69 \\
\hline
\end{tabular}

Test Statistics

\begin{tabular}{lll}
\hline & Chi-Square & Asymp. Sig. \\
\hline $\begin{array}{l}\text { Scores of four elements } \\
\text { applied by NEFLT }\end{array}$ & 11.845 & .016 \\
$\begin{array}{l}\text { Scores of four elements } \\
\text { applied by LEFLT }\end{array}$ & 11.795 & .014 \\
\hline
\end{tabular}

Note: NEFLT $=$ native EFL teacher, LEFLT $=$ local EFL teacher, $2=$ examples used in the classroom, $3=$ mistake correction, $8=$ academic writing, $10=$ teaching innovation, $\mathrm{N}=$ number of subjects.

Table 6 showed that the significance of four cultural continuity elements was $0.016<0.05$ for NEFLTs, and $0.014<0.05$ for LEFLTs. Therefore, the authors could claim that there was a significant difference among the four elements that affect the teaching models applied by both NEFLTs and LEFLTs, demonstrating that there was a cultural continuity in the international program in GDUFS generally. The overall mean rank scores of examples, mistake correction, academic writing and teaching innovation were $115.47,98.55,155.32$ and 104.48 for NEFLTs, which suggested that the application of academic writing was significantly more dominated than the other cultural continuity elements, followed by the use of Western examples, teaching innovation and mistake correction. As for LEFLTs, mistakes correction (176.38) significantly outperformed the use of Western examples (103.65), teaching innovation (95.69) and academic writing (96.08), which illustrated that the effect of element 3 was more applied than the other three elements by LEFLTs. The results suggested that, among the four elements, NEFLTs paid more attention to academic writing, while LEFLTs spent more time in correcting students' mistakes in classroom. The results demonstrated that even though both NEFLTs and LEFLTs consistently applied the four elements to their teaching, there were micro differences concerning their teaching modes and preferences in international programs of higher education in GDUFS.

\subsection{Cultural Continuity Realized in the International Program}

Both NEFLTs and LEFLTs contribute (in)consistency in Western cultural continuity of higher education applied in the international programs in China, i.e. NEFLTs and LEFLTs demonstrate asymmetrical adaptation to local culture and foreign culture in their teaching and form an integrated cultural continuity teaching mode in China (see Figure 2). In the practice, LEFLTs' adaptation to Western education modes is moderate, mixing and selective on one hand, and on the other hand, they know that many Chinese students will come back home after their graduation and the students should have certain professional knowledge about the local working environment. Therefore, LEFLTs apply local Chinese cases in their teaching, and using Chinese thinking patterns and problem resolutions in teaching frequently. Interestingly, NEFLTs integrate their understanding and learning experience about Chinese education system and students' learning culture into their teaching too. NEFLTs require students to do lots of homework, memorize the terms and theories and correct their mistakes frequently in students' 
presentations. The mixed application of both Western and local teaching cultures and methods in Chinese teaching environment influences and underpins Chinese students' understanding and cognition of international higher education before they go abroad, reflecting that local teaching and learning tradition have eventually involved in the internationalization of higher education.

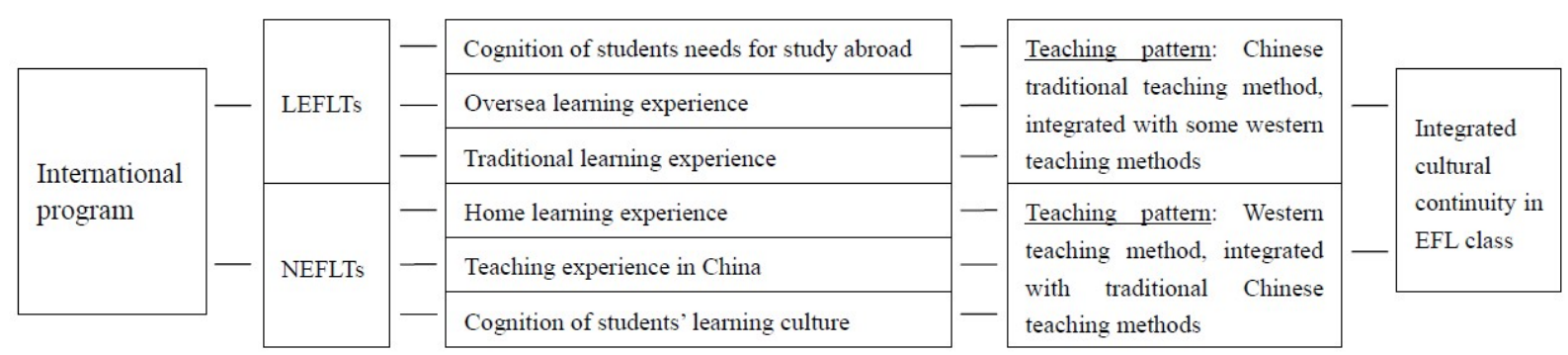

Figure 2. An integrated cultural continuity application in EFL teaching in China

Owning to cultural diversities of higher education in different countries, hardly can researchers or educators conclude what standards or specific requirements of teaching criteria, pedagogy or curriculum should be applied in international higher education, nor can they differentiate what teaching culture should be utilized to maintain the cultural continuity in international higher education. As Sussman (2000) and O'Sullivan-Lago et al. (2008) see it, cultural continuity provides the resources one draws upon to create cultural identities, imperceptibly forming a mental framework through which individuals define their ontology, motivate and select their behaviors, and judge and evaluate the behaviors of others. However, the weight of teaching patterns applied by both NEFLTs and LEFLTs in international programs in China in fact is not equal. According to the research results, the holistic picture of cultural continuity applied in the international programs in China can be seen in Figure 3 .

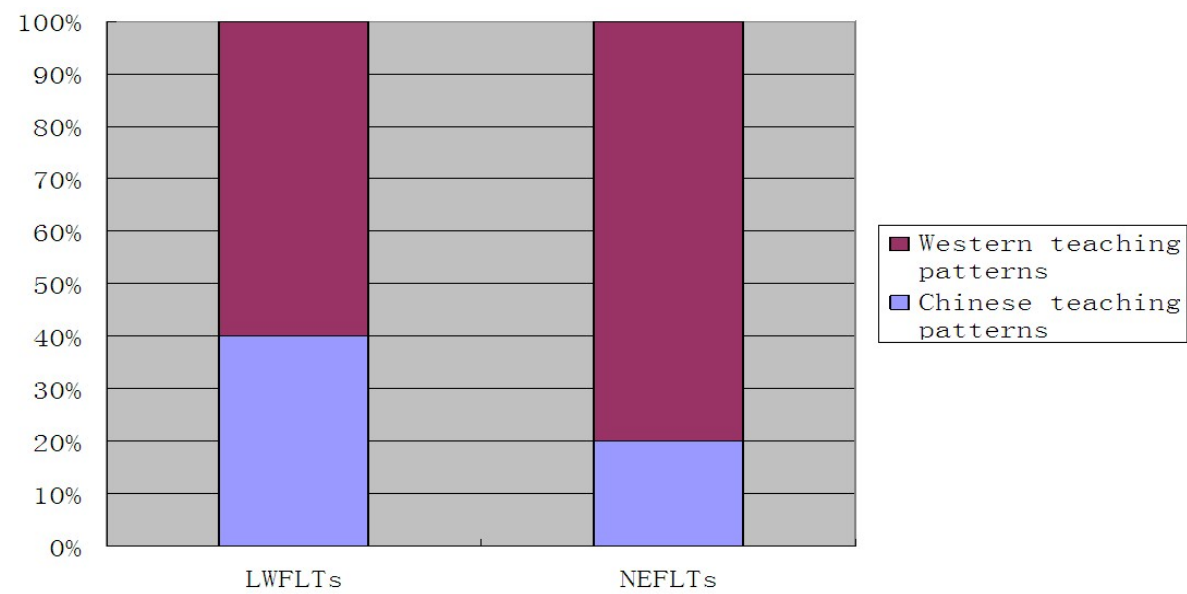

Figure 3. Cultural continuity realized in the international program

The newly integrated teaching pattern in international higher education in China is very dynamic. How Western teaching continuity and local Chinese teaching continuity are applied by both NEFLTs and NEFLTs depends on the overall teaching contexts defined by Brown (2000): the teachers, the learners, the learners' parents, the teachers' peers, the teacher administrators, society as a whole - all have the role of the teacher and his or her learners. At the cross-cultural level, the analysis of cultural continuity in class taught by teachers from different cultural backgrounds also prove that NEFLTs and LEFLTs are apt to their domain knowledge which includes the concepts, facts and procedures explicitly identified with a particular subject matter, which is generally explicated in textbooks, class-activity management and teaching patterns.

\section{Conclusion}

Exploring the teaching continuity at a cultural level offers opportunities for local universities and teachers to 
work with international ones and participate in the internationalization of higher education. Teachers' experience of cultural continuity in classroom will preconceive students' beliefs about courses which are taught and operated abroad; meanwhile, students' learning experience in the local cultural environment may affect the variety and flexibility of their learning strategies in their future studies abroad, and even work after graduation. This echoes Abraham and Vann's (1987) suggestions on cultural issues and learning strategies. Holliday (2001:169) points out that "a major obstacle to true cultural continuity is our own professional discourses which prevent us from seeing the real worlds of the people we work with. We, therefore, need to be critically aware of ourselves as cultural actors and learn how to see the people we work with in their own terms instead of in our terms." Cultural continuity is cultural appropriateness in EFL teaching and learning. Both local teachers and foreign teachers should be aware of local and international cultures, different educational systems and their critical applications in EFL teaching and learning environment of higher education.

\section{Acknowledgement}

The research is supported by the Major Grant of the National Key Research Centers for Philosophy and Social Sciences, Ministry of Education, China (No. 14JJD740011), as well as the MOE Project of the Center for Linguistics and Applied Linguistics, Guangdong University of Foreign Studies.

\section{References}

Abraham, R. G., \& Vann, R. J. (1987). Strategies of two language learners: A case study. In A. L. Wenden, \& J. Rubin (Eds.), Learner Strategies in Language Learning (pp. 85-102). NJ: Prentice-Hall, Englewood Cliffs.

Blum-Kulka, S., House, J., \& Kasper, G. (1989). Cross-cultural pragmatics: Requests and apologies. Norwood, NJ: Ablex.

Brown, R. (2000). Cultural continuity and ELT teacher training. ELT Journal, 54(3), $227-234$. http://dx.doi.org/10.1093/elt/54.3.227

Chandler, M. J., \& Proulx, T. (2006). On committing the psychologist's fallacy and getting away with it: Bridging personal and cultural identities. In P. K. Oles, \& H. Hermans (Eds.), The Dialogical Self: Theory and Research (pp. 2-15). Wydawnictwo: KUL.

Ferdman, B. M., \& Horenczyk, G. (2000). Cultural identity and immigration: Reconstructing the group during cultural transitions. In E. Olshtain, \& G. Horenczyk (Eds.), Language, Identity and Immigration (pp. 81-100). Jerusalem: Hebrew University Magnes Press.

Hofstede, G. (1986). Cultural differences in teaching and learning. International Journal of Intercultural Relations, 10(3), 301-320. http://dx.doi.org/10.1016/0147-1767(86)90015-5

Holliday, A. (1997). Six lessons: Cultural continuity in communicative language teaching. Language Teaching Research, 1(3), 212-238. http://dx.doi.org/10.1177/136216889700100303

Holliday, A. (2001). Achieving cultural continuity in curriculum innovation: Dealing with dominant discourses. In D. R. Hall, \& A. Hewings (Eds.), Innovation in English Language Teaching: A Reader (pp. 169-176). London: Routledge.

Jacob, G. (1996). The CDS co-ordinator (Unpublished paper). Pune University, India.

Kasper, G. (2000). Data collection in pragmatics research. In H, Spencer-Oatey (Ed.), Culturally Speaking: Managing Rapport through Talk across Cultures (pp. 316-369). London: Continuum.

Marton, F. M., Watkins, D., \& Tang, C. (1997). Discontinuities and continuities in the experience of learning: An interview study of high-school students in Hong Kong. Learning and Instruction, 7(1), 21-48. http://dx.doi.org/10.1016/S0959-4752(96)00009-6

O’Sullivan-Lago, R., de Abreu, G., \& Burgess, M. (2008). 'I am a human being like you': An identification strategy to maintain continuity in cultural contact zone. Human Development, 51, 349-367. http://dx.doi.org/10.1159/000170897

Phillipson, R. (1992). Linguistic imperialism. Oxford: Oxford University Press.

Qi, Y., \& Ding, Y. (2011). Use of formulaic sequences in monologues of Chinese EFL learners. System, 39, 164-174. http://dx.doi.org/10.1016/j.system.2011.02.003

Shamim, F. (1996). In and out of the action zone: Location as a feature of interaction in large ESL classes in Pakistan. In K. M. Bailey, \& D. Nunan (Eds.), Voices from the Language Classroom (pp. 123-144). Cambridge: Cambridge University Press. 
Spradley, J. P. (1980). Participant observation. New York: Holt, Rinehart and Winston.

Sussman, N. M. (2000). The dynamic nature of cultural identity throughout cultural transitions: Why home is not so sweet. Personality and Social Psychology Review, 4, 355-373. http://dx.doi.org/10.1207/S15327957PSPR0404_5

Thornton, R. J. (1988). The rhetoric of ethnographic holism. Cultural Anthropology, 3(3), 285-303. http://dx.doi.org/10.1525/can.1988.3.3.02a00050

Wiggins, D. (1980). Sameness and substance. Cambridge, MA: Harvard University Press.

Yang, N. D. (1999). The relationship between EFL learners' beliefs and learning strategy use. System, 27, 515-535. http://dx.doi.org/10.1016/S0346-251X(99)00048-2

Yang, W. X., \& Sun, Y. (2012). The use of cohesive devices in argumentative writing by Chinese EFL learners at different proficiency levels. Linguistic and Education, 23, 31-48. http://dx.doi.org/10.1016/j.linged.2011.09.004

\section{Copyrights}

Copyright for this article is retained by the author(s), with first publication rights granted to the journal.

This is an open-access article distributed under the terms and conditions of the Creative Commons Attribution license (http://creativecommons.org/licenses/by/3.0/). 